\title{
Role of hysterosalpingography in evaluation of tubal factors and its comparison with sonosalpingography
}

\author{
Rainee Agrawal*, Deepti Shrivastava
}

\begin{abstract}
Department of Obstetrics and Gynecology, Datta Meghe Institute of Medical Sciences University, Sawangi, Wardha,
\end{abstract} Maharashtra, India

Received: 18 October 2016

Accepted: 15 November 2016

\section{*Correspondence:}

Dr. Rainee Agrawal,

E-mail: rainee2280@gmail.com

Copyright: (C) the author(s), publisher and licensee Medip Academy. This is an open-access article distributed under the terms of the Creative Commons Attribution Non-Commercial License, which permits unrestricted non-commercial use, distribution, and reproduction in any medium, provided the original work is properly cited.

\begin{abstract}
Background: Laparoscopy is considered as the gold standard for assessment of tubal factors of infertility, although because of its invasive nature, cost and the need for anaesthesia and hospitalization, HSG seems to be a basic routine procedure for tubal factors. Currently with the availability of the ultrasonography machines with very good resolution, SSG can be simultaneously practiced with ultrasonography during day 7-9 of the menstrual cycle to assess tubal patency. Hence, the present study was designed to compare the accuracy of HSG with SSG for evaluation of tubal factor infertility.

Methods: This was a prospective cross-sectional study of 100 consecutive women with primary or secondary infertility without active pelvic infection, selected from OPD of Department of Obstetrics and Gynaecology, Acharya Vinoba Bhave Rural Hospital associated with Datta Meghe Institute of Medical Sciences University, Sawangi (Meghe), Wardha over a period of two years from September 2014 to August 2016.

Results: In the present study for diagnosing tubal patency SSG had sensitivity of $88.64 \%$, specificity of $75 \%$, positive predictive value of $96.29 \%$ and negative predictive value of $47.36 \%$ and diagnostic accuracy of $87 \%$, while HSG had sensitivity of $94.32 \%$, specificity of $83.33 \%$, positive predictive value of $97.64 \%$ and negative predictive value of $66.66 \%$ and diagnostic accuracy of $93 \%$.

Conclusions: Initial assessment of tubal patency by HSG is better than SSG as an indirect, outdoor, non-invasive procedure although with minimal radiation hazards. It allows documentation of tubal patency enables detection of several tubal lesions and permits assessments of the fine intratubal architectural details as well as little uterine pathology. It will help in reducing the number of laparoscopic procedures and their related complications and health care costs for confirmation of tubal patency.
\end{abstract}

Keywords: HSG, SSG

\section{INTRODUCTION}

The oviduct or fallopian tube is the anatomical region where every new life begins in a mammalian species. After a long journey, the spermatozoa meet the oocyte in the specific site of the oviduct named ampulla, and fertilization takes place. Hence tubal factors play an important role in fertility. Infertility as such is a critical component of reproductive health and has often been neglected in government health care programmes, maybe because in developing countries population explosion is a bigger issue. ${ }^{1}$
The number of couples seeking medical help for infertility is increasing dramatically. ${ }^{2}$ It is a common problem that baffles Gynaecologists. In general infertility work-up considered being involved with high cost and day by day there is an increase in demand for diagnostic and therapeutic investigations for management of infertility. With increasing number of advanced infertility care centers in India sometimes basic noninvasive assessment of tubal factors is ignored or bypassed.

Tubal pathology is one of the main causes of infertility contributing $20-40 \%$ of female infertility cases. ${ }^{3}$ 
Hysterosalpingography is a procedure that provides information not only about the tube but also about the uterine cavity and cervical canal. The term Hysterosalpingography is a combination of a Greek word Hystero-uterus, salphinx-trumpet, graphein-to write. ${ }^{4}$

Uterine abnormalities that can be detected by HSG include congenital anomalies, intrauterine polyps, submucous leiomyomas, surgical changes and synechiae. Tubal abnormalities that can be detected include proximal or distal tubal occlusion, salpingitis isthmica nodosum, polyps, hydrosalpinx and peritubal adhesions. ${ }^{5}$

Sonosalpingography is the ultrasonic visualization of the Fallopian tubes using ultrasound echo enhancing (contrast) agents. This test is used as a basic screening test for evaluating tubal patency in all infertile cases. Sonosalpingography also known as Sion Test uses transvaginal sonography to confirm the tubal patency by visualizing the spill of fluid from the fimbrial end of the Fallopian tubes. Normally the Fallopian tubes are isoechoic and are not visualized unless pathological or surrounded by fluid.

Sonosalpingography can also be used to evaluate the endometrium besides the Fallopian tubes. The injection of fluid into the endometrial canal (uterine cavity) after deflating the Foley's balloon, improves visualization of the masses such as polyps and sub mucus fibroids. Adhesions (synechae) can also be well seen, it is a noninvasive, cheap, outdoor screening procedure in patients with infertility without any radiation exposure. ${ }^{6}$

Considering the advantages and disadvantages of hysterosalpingography and sonosalpingography the present study was undertaken to the diagnostic accuracy of tubal patency amongst infertile women by hysterosalpingography and to compare it with sonosalpingography.

\section{METHODS}

This was a prospective cross-sectional study of 100 consecutive women with primary or secondary infertility without active pelvic infection, selected from OPD of Department of Obstetrics and Gynaecology, Acharya Vinoba Bhave Rural Hospital associated with Datta Meghe Institute of Medical Sciences University, Sawangi (Meghe), Wardha over a period of two years from September 2014 to August 2016.

Women with a history of primary or secondary infertility, without any active genital tract infection and willing to participate in the study and who were planned to be assessed by diagnostic laparoscopy for basic infertility work-up were included.

In the first visit, the couple was explained in detail about the normal physiology and the fertile period.
They were subjected to detailed history pertaining to infertility, menstrual cycle, obstetric events, personal and family history along with any treatment history for both male and female partners. Routine blood and urine test was done for both the partners. The women were subjected to clinical examination, including detailed general as well as gynaecological examination, which included per speculum and per vaginum examination to rule out any active infection. Women with cervical erosion/other pathologies or abnormal white discharge per vaginum were subjected to Pap smear and high vaginal swab testing, and were asked to collect the report after 7 days. These women were treated according to the reports and were called in the next cycle.

Women who were planned and given fitness by anaesthetist for laparoscopy and fulfilling the inclusion criteria were explained about the procedure of both HSG and SSG and their appointment for the same was taken from the Interventional Radiology department, after obtaining their written, informed and valid consent.

During day 6 to day 9 of menses their sonosalpingography followed by fluoroscopic hysterosalpingography was done on the same day.

Prior to the procedure analgesics i.e. Diclofenac suppository per rectal and injection Buscopan intramuscular were given.

Their laparoscopy was done as planned the next day and findings of HSG and SSG were then correlated with laparoscopic findings by taking it as a standard reference.

\section{$S S G$}

The procedure involved instillation of normal saline into the endometrial cavity through the cervix using pediatric Foley's catheter and inspection of free fluid in pouch of Doulas through transvaginal sonography.

The vulva and the vagina were cleaned with an antiseptic solution after giving dorsal position.

Sim's speculum was used to retract the posterior vaginal wall and anterior vaginal wall retractor was used to retract the anterior vaginal wall. A pediatric Foley's catheter of no. 8 size was introduced through the cervix up to the internal os and the balloon was distended with 2 $\mathrm{ml}$ of normal saline to prevent retrograde leakage of saline in the vagina.

For sonography Aloka prosound alpha 7 machine was used. The speculum was then removed and the transvaginal transducer inserted into the vagina. The catheter's position in the endometrial cavity was identified and it was repositioned if necessary. About 50 $100 \mathrm{ml}$ sterile saline was then injected slowly through the catheter under continuous sonographic control. The uterus was scanned systematically in sagittal and coronal 
planes to delineate the entire endometrial cavity, abnormalities of the uterine wall, adenaxal pathologies like hydrosalpinx and ovarian cysts etc. and appropriate images were recorded. Pouch of Douglas was examined for free fluid after instillation of normal saline for confirmation of tubal patency. Foley's catheter was left in place for HSG examination.

After SSG the patients were subjected to HSG examination.

\section{$H S G$}

Our institute is equipped with advanced Interventional radiology Lab and fluoroscopic monitor (PHILIPS ALLURA XPER FD-20). For HSG patients were sent to the Interventional radiology lab and were placed in the dorsal position. Cleaning, painting and draping with antiseptic solution was done. Speculum was inserted to confirm the position of Foley's catheter.

Precautions were taken to completely remove the air from the catheter, and the catheter was tightly made to fix to the cervix. The speculum was then removed andthe patient was carefully moved up to the table so that she lied in supine position. The position of the catheter was again confirmed by fluoroscopy. About $5 \mathrm{ml}$ of Iohexol contrast was taken into $20 \mathrm{ml}$ disposable syringe along with $10 \mathrm{ml}$ normal saline. The syringe was fixed to the connected end of the catheter. The contrast was injected slowly using low, steady pressure with constant fluoroscopic monitoring of uterine and tubal filling.

Exposure was taken under fluoroscopic control as follows:

- Immediately after injection of 3-4ml to demonstrate the uterine cavity.

- After instillation of another 4- $5 \mathrm{ml}$ to demonstrate tubal spillage into the peritoneal cavity.

Laparoscopy was performed the next day under general anesthesia, twenty $\mathrm{ml}$ of $0.5 \%$ methylene blue was injected using Leech Wilkinson's cannula to test tubal patency by visualizing the blue colored dye coming out from the fimbrial end of the Fallopian tube.

The data obtained by transvaginal sonosalpingography, hysterosalpingography and laparoscopy for each case were recorded and tabulated in a pre-structured proforma for the study.

Statistical analysis was done by using descriptive and inferential statistics using Chi-Square test, binary classification and the software used was SPSS 17.0 version, graph pad prism 5.0 version and $\mathrm{p}<0.05$ is considered as level of significance.

\section{RESULTS}

Table 1: Distribution of women, according to age.

\begin{tabular}{|llll|}
\hline $\begin{array}{l}\text { Age } \\
\text { (years) }\end{array}$ & $\begin{array}{l}\text { Primary } \\
\text { infertility } \\
n=63\end{array}$ & $\begin{array}{l}\text { Secondary } \\
\text { infertility } \\
n=37\end{array}$ & Total \\
\hline$<=25$ & $33(52.38 \%)$ & $4(10.81 \%)$ & $37(37 \%)$ \\
\hline $26-30$ & $21(33.33 \%)$ & $21(56.76 \%)$ & $42(42 \%)$ \\
\hline $31-35$ & $7(11.11 \%)$ & $6(16.22 \%)$ & $13(13 \%)$ \\
\hline$>=36$ & $2(3.17 \%)$ & $6(16.22 \%)$ & $8(8 \%)$ \\
\hline Mean \pm SD & $\begin{array}{l}26.91 \pm 4.27 \\
\text { years }\end{array}$ & $\begin{array}{l}29.51 \pm 4.31 \\
\text { years }\end{array}$ & $\begin{array}{l}27.69 \pm 4.48 \\
\text { years }\end{array}$ \\
\hline & & & \\
\hline
\end{tabular}

Table 1 shows that in the present study, the mean age of women was $27.69 \pm 4.48$ years, for primary infertility the mean age was $26.91 \pm 4.27$ years and for women of secondary infertility the mean age was $29.51 \pm 4.31$ years.

Table 2: Distribution of women, according to type of infertility.

\begin{tabular}{|lll|}
\hline $\begin{array}{l}\text { Type of } \\
\text { infertility }\end{array}$ & $\begin{array}{l}\text { Number } \\
(\mathbf{n = 1 0 0 )}\end{array}$ & Percentage $(\%)$ \\
\hline Primary & 63 & 63.00 \\
\hline Secondary & 37 & 37.00 \\
\hline Total & 100 & 100.00 \\
\hline
\end{tabular}

Table 2 shows distribution of women, according to type of infertility, 63 women (63\%) were of primary infertility and 37 women (37\%) were of secondary infertility.

Table 3: Tubal patency amongst the women of study group, according to SSG, HSG and laparoscopy.

\begin{tabular}{|llll|}
\hline Test & $\begin{array}{l}\text { SSG } \\
(\mathrm{n}=100)\end{array}$ & $\begin{array}{l}\text { HSG } \\
(\mathrm{n}=100)\end{array}$ & $\begin{array}{l}\text { Laparoscopy } \\
(\mathrm{n}=100)\end{array}$ \\
\hline $\begin{array}{l}\text { Bilateral } \\
\text { or }\end{array}$ & $81(81 \%)$ & $85(85 \%)$ & $88(88 \%)$ \\
$\begin{array}{l}\text { unilateral } \\
\text { tubal } \\
\text { patency } \\
(\mathrm{n}=100)\end{array}$ & & & \\
\hline $\begin{array}{l}\text { Bilateral } \\
\text { block } \\
(\mathrm{n}=100)\end{array}$ & $19(19 \%)$ & $15(15 \%)$ & $12(12 \%)$ \\
\hline
\end{tabular}

Table 4: Side of tubal block in HSG and laparoscopy.

\begin{tabular}{|llll|}
\hline & & $\begin{array}{l}\text { HSG } \\
(\mathbf{n = 1 0 0})\end{array}$ & $\begin{array}{l}\text { Laparoscopy } \\
(\mathrm{n}=100)\end{array}$ \\
\hline Bilateral patent & $\begin{array}{l}66(66 \%) \\
70(\%)\end{array}$ \\
\hline \multirow{2}{*}{$\begin{array}{l}\text { Unilateral } \\
\text { block }\end{array}$} & $\begin{array}{l}\text { Right sided } \\
\text { block }\end{array}$ & $\begin{array}{l}10 \\
(10 \%)\end{array}$ & $10(\%)$ \\
\cline { 2 - 4 } & $\begin{array}{l}\text { Left sided } \\
\text { block }\end{array}$ & $9(9 \%)$ & $8(8 \%)$ \\
\hline $\begin{array}{l}\text { Bilateral } \\
\text { block }\end{array}$ & $\begin{array}{l}15 \\
(15 \%)\end{array}$ & $12(12 \%)$ \\
\hline
\end{tabular}


Table 3 and 4 show that SSG was not able to determine the side of tubal block and could only detect either unilateral or bilateral tubal patency in 81 women which was confirmed by observing free fluid in pouch of Douglas. It could detect bilateral tubal blockage in 19 women, which was confirmed by the absence of free fluid in pouch of Douglas.

HSG in the present study demonstrated bilateral tubal patency in $66 \%$ women, unilateral tubal patency in $19 \%$ women, amongst them, $10 \%$ women had left sided tubal patency and $9 \%$ women had right sided patency while $15 \%$ women had a bilateral tubal block.

Table 5: Correlation of SSG and laparoscopy (taking laparoscopy as the gold standard).

\begin{tabular}{|llll|}
\hline SSG & $\begin{array}{l}\text { Laparoscopy } \\
\text { Unilateral or } \\
\text { bilateral tubal } \\
\text { patency }\end{array}$ & $\begin{array}{l}\text { Bilateral } \\
\text { tubal } \\
\text { block }\end{array}$ & \\
\hline $\begin{array}{l}\text { Unilateral or } \\
\text { Bilateral } \\
\text { tubal } \\
\text { patency }\end{array}$ & $78(78 \%)$ & $3(3 \%)$ & $81(81 \%)$ \\
\hline $\begin{array}{l}\text { Bilateral } \\
\text { tubal block }\end{array}$ & $10(10 \%)$ & $9(9 \%)$ & $19(19 \%)$ \\
\hline Total & $88(88 \%)$ & $12(12 \%)$ & $100(100 \%)$ \\
\hline
\end{tabular}

- $\quad$ Sensitivity $=88.64 \%$

- $\quad$ Specificity $=75 \%$

- $\quad$ Positive predictive value $=96.2963 \%(95 \% \mathrm{CI}=89$. 667 to $98.732 \%$ )

- $\quad$ Negative predictive value $=47.3684 \%(95 \% \mathrm{CI}=27$. 329 to $68.292 \%$ )

- $\quad$ Diagnostic accuracy $=87 \%$

- $\quad$ Positive test $=$ Including either unilateral or bilateral tubal patency

- $\quad$ Negative test $=$ Bilateral tubal occlusion

Table 6: Correlation of HSG and Laparoscopy (taking laparoscopy as the gold standard).

\begin{tabular}{|llll|}
\hline SSG & Laparoscopy & & Total \\
& $\begin{array}{l}\text { Unilateral or } \\
\text { Bilateral tubal } \\
\text { patency }\end{array}$ & $\begin{array}{l}\text { Bilateral } \\
\text { tubal } \\
\text { block }\end{array}$ & \\
\hline $\begin{array}{l}\text { Unilateral or } \\
\text { Bilateral } \\
\text { tubal } \\
\text { patency }\end{array}$ & $83(83 \%)$ & $2(2 \%)$ & $85(85 \%)$ \\
\hline $\begin{array}{l}\text { Bilateral } \\
\text { tubal block }\end{array}$ & $5(5 \%)$ & $10(10 \%)$ & $15(15 \%)$ \\
\hline Total & $88(88 \%)$ & $12(12 \%)$ & $100(100 \%)$ \\
\hline
\end{tabular}

- $\quad$ Sensitivity $=94.32 \%$

- Specificity $=83.33 \%$

- $\quad$ Positive predictive value $=97.647 \%(95 \% \mathrm{CI}=91$. 821 to $99.352 \%$ )
- $\quad$ Negative Predictive Value $=66.66 \%(95 \% \quad \mathrm{CI}=41$. 713 to $84.823 \%$ )

- $\quad$ Diagnostic accuracy $=93 \%$

- $\quad$ Positive test $=$ Including either unilateral or bilateral tubal patency

- $\quad$ Negative test $=$ Bilateral tubal occlusion

Table 5 and 6 show that in the present study for diagnosing tubal patency SSG had sensitivity of $88.64 \%$, specificity of $75 \%$, positive predictive value of $96.29 \%$ and negative predictive value of $47.36 \%$ and diagnostic accuracy of $87 \%$, while HSG had sensitivity of $94.32 \%$, specificity of $83.33 \%$, positive predictive value of $97.64 \%$ and negative predictive value of $66.66 \%$ and diagnostic accuracy of $93 \%$.

Table 7: Findings according to site of block in HSG and laparoscopy.

\begin{tabular}{|c|c|c|c|}
\hline Site & $\begin{array}{l}\text { HSG } \\
(\mathrm{n}=34)\end{array}$ & $\begin{array}{l}\text { Laparoscopy } \\
(\mathrm{n}=\mathbf{3 0})\end{array}$ & P-value \\
\hline Proximal & $18(52.94 \%)$ & $17(56.66 \%)$ & $\begin{array}{l}0.32, p= \\
0.56, \mathrm{NS}\end{array}$ \\
\hline $\begin{array}{l}\text { Mid- } \\
\text { segmental }\end{array}$ & $3(8.82 \%)$ & 0 & $\begin{array}{l}9.42, p= \\
0.0042, S\end{array}$ \\
\hline $\begin{array}{l}\text { Distal } \\
\text { (Fimbrial) }\end{array}$ & $6(17.64 \%)$ & $7(23.33 \%)$ & $\begin{array}{l}0.76, p= \\
0.38, \mathrm{NS}\end{array}$ \\
\hline Combined & $7(20.58 \%)$ & $6(20 \%)$ & $\begin{array}{l}0.03, p= \\
0.86, N S\end{array}$ \\
\hline
\end{tabular}

Table 7 shows that HSG could determine the site of tubal block, as $18(52.94 \%)$ women had a proximal tubal block, $3(8.82 \%)$ women had mid-segmental tubal block, 6 (17.64\%) women had distal tubal block while 7 (20.58\%) had combined tubal block in which either proximal, midsegmental, or distal block was seen in either of the two tubes. On confirmation with laparoscopy it was found that proximal tubal block was seen in $17(56.66 \%)$ women, distal tubal block was seen in $7(23.33 \%)$ women and combined block was seen in $6(20 \%)$ women. Mid segmental blocks in laparoscopy were inconclusive.

Table 8: Other associated pathologies.

\begin{tabular}{|llll|}
\hline & HSG & SSG & Laparoscopy \\
\hline Hydrosalpinx & $8(8 \%)$ & $2(2 \%)$ & $10(10 \%)$ \\
\hline Beaded tubes & $1(1 \%)$ & $0(0 \%)$ & $1(1 \%)$ \\
\hline Uterine fibroid & $2(2 \%)$ & $11(11 \%)$ & $11(11 \%)$ \\
\hline Uterine polyp & $1(1 \%)$ & $3(3 \%)$ & $4(4 \%)$ \\
\hline $\begin{array}{l}\text { Bicornuate } \\
\text { uterus }\end{array}$ & $2(2 \%)$ & $1(1 \%)$ & $2(2 \%)$ \\
\hline $\begin{array}{l}\text { Septate/arcuate } \\
\text { uterus }\end{array}$ & $2(2 \%)$ & $1(1 \%)$ & $2(2 \%)$ \\
\hline Ovarian cysts & $0(0 \%)$ & $19(19 \%)$ & $20(20 \%)$ \\
\hline
\end{tabular}

Table 8 shows that Hydrosalpinx was seen in 8 women in HSG and in 2 women in SSG. 1 woman had beaded tube that could be seen in HSG. Uterine fibroid was seen in 2 women in HSG while SSG could detect it in 11 women. 
Uterine polyp was seen in 1 woman in HSG and in 3 women in SSG. Bicornuate uterus was seen in 2 women in HSG and in 1 woman in SSG. 2 women had a septate uterus in HSG and in SSG septate uterus was seen in 1 woman. SSG was also able to detect ovarian cyst in 19 women.

On confirmation of the findings of HSG and SSG by laparoscopy it was found that hydrosalpinx was seen in 10 women, convoluted tube in 1 women, 11 women had uterine fibroid, 4 women had uterine polyp, 2 women had bicornuate uterus and septate uterus each while 20 women had ovarian cysts.

\section{DISCUSSION}

Mean of infertility in the study done by Raj $\mathrm{N}$ et al was $26.67 \pm 4.15$ years and in study done by Tabbakhet MNE et al, it was $27.6 \pm 4.25$ years for primary infertility group and $29.8 \pm 4.1$ years for secondary infertility group. ${ }^{7,8}$

Raj $\mathrm{N}$ et al in his study had $70 \%$ women of primary infertility and $30 \%$ women of secondary infertility.

Suttipichate $\mathbf{J}$ et al also reported that transvaginal saline SSG showed tubal patency (either unilateral or bilateral) in 33 women and bilateral tubal occlusion in 9 women, they also stated that SSG could not detect the side of tubal blockage and detect patency of at least one fallopian tube by demonstrating the collection of free fluid in cul de sac and concluded that accuracy in establishing which tube was patent was not in their scope because it was time consuming and needed extra skill for interpretation. ${ }^{9}$

Raj $\mathrm{N}$ et al found that in HSG $66 \%$ women had bilateral patent tubes, $20 \%$ women had a bilateral tubal block while $14 \%$ had a unilateral tubal block, whereas in SSG 70.83\% women had bilateral tubal patency, $20.83 \%$ women had a bilateral tubal block while $8.34 \%$ women had a unilateral tubal block. ${ }^{7}$

This discrepancy of diagnosing tubal blockage and patency between SSG and HSG could be attributed to spasm at cornu, intra-luminal debris, motility disorders, technical error, or human error and also false positive results (the tube was blocked by HSG and patent by SSG) this could be due to hydrosalpinx which may itself be the reason for the turbulence of the flow of the saline through the dilated tubes may simulate spillage on ultrasound scan.

Singhal A et al found that, for diagnosis of patent tubes, sensitivity of sonosalpingography was $96.7 \%$ and specificity was $87.5 \%$ whereas positive predictive value was found to be $93.75 \% .^{10}$

Hajishafiha $M$ et al found the sensitivity, specificity, positive predictive value (PPV), and negative predictive value (NPV) of SHG in comparison with laparoscopy were $94 \%, 100 \%, 100 \%$, and $75 \%$, respectively. ${ }^{11}$
Gandotra $\mathrm{N}$ et al compared HSG findings of tubal patency with laparoscopic chromopertubation and found a sensitivity of $90.91 \%$ (95\% CI: 76.43-96.86) and the specificity was $77.78 \%$ (95\% CI 59.24-89.39) when tubal block was defined as any form be it unilateral or bilateral. $^{12}$ The positive and negative predictive values were $83.33 \%$ (95\%CI 68.11-92.13) and $87.50 \%$ (95\%CI 69.0- 95.66) respectively. The false positive and false negative rates were $10 \%$ and $5 \%$ respectively; whereas Malik B et al found that SSG had a sensitivity of $95.83 \%$ and specificity of $100 \%$ for evaluation of tubal patency. In contrast, in HSG for evaluation of tubal patency, the sensitivity is $91.67 \%$ and specificity is $100 \% .^{13}$

Geetha V et al found in their study that, HSG detected 8 women with proximal tubal block, 24 women with a block at mid segment and 16 women with Fimbrial block. $^{14}$

Seal SL et al did a study in which Hydrosalpinx was detected in 6 women by SSG, in 5 women by HSG and in 8 women by laparoscopy, tuboovarian mass was detected in 4 women by SSG and in 2 women by laparoscopy, endometriosis was seen in 4 women in SSG and in 5 women by laparoscopy, peritubal adhesions was seen only by laparoscopy in 4 women, fibroid uterus was seen in 2 women by SSG and in 4 women by laparoscopy, whereas ovarian cysts and polycystic ovaries were seen in 6women by SSG, in 2 women by HSG and in 8 women by laparoscopy and concluded that pelvic pathologies were better detected by laparoscopy than by SSG and HSG and SSG detected more pelvic pathology than HSG. ${ }^{15}$

The most advantageous screening infertility protocol necessitate methods that are diagnostically accurate, timely, cost-effective, reliable and minimally invasive.

In our study the sensitivity and specificity of SSG was less than HSG and at the same time SSG was very subjective and skill dependent, hence it cannot be adopted to replace HSG as a basic non-invasive assessment of tubal factor infertility.

\section{CONCLUSION}

Initial assessment of tubal patency by HSG is better than SSG as an indirect, outdoor, non-invasive procedure although with minimal radiation hazards. It allows documentation of tubal patency enables detection of several tubal lesions and permits assessments of the fine intratubal architectural details as well as little uterine pathology. It will help in reducing the number of laparoscopic procedures and their related complications and health care costs for confirmation of tubal patency.

\section{ACKNOWLEDGEMENTS}

We would like to thank the institute to allow us to carry out this study and women who participated in this study. 
Funding: No funding sources

Conflict of interest: None declared

Ethical approval: The study was approved by the Institutional Ethics Committee

\section{REFERENCES}

1. Sembuya R. Mother or nothing: the agony of infertility. Bull World Health Organ. 2010;88:881-2.

2. Aral SO, Cates W. The increasing concern with infertility: Why now? JAMA. 1983;250(17):232731.

3. Aubuchon M, Burney O. Infertility and Assisted Reproductive Technology. In: Novak E. Berek and Novak's gynecology. Berek JS, editor. Lippincott Williams and Wilkins; 2007. page 6627.

4. Subbarao K. Presidential address at the 52 nd annual congress of Indian radiological and imaging association. Indian Journal of Radiology and Imaging. 1999;9(1):3.

5. Khan MI, Jesmin S, Jerin J, Shermin S, Chowdhury TA. Hysterosalpingography in Infertility. Delta Medical College Journal. 2014;2(1):9-12.

6. Malhotra N, Malhotra J, Mittal S, Singh A. Sonosalpingography. Nepal Journal of Obstetrics and Gynaecology. 2006;1(2):71-3.

7. Raj N, Sonowal R. Comparative study of Hysterosalpingography and Sonohysterosalpingography in the evaluation of fallopian tube patency in routine infertility assessment. International Journal of Recent Trends in Science and Technology. 2015;16(3):494-8.

8. El-Tabbakh MN, Slamka P. Transvaginal sonohysterography (Tv-Sh), Versus hysterosalpingography (Hsg) And laparoscopy. Available from: http://hcp.obgyn.net/ laparoscopy/content/article/1760982/1896801\#.

2011.

9. Suttipichate J, Sroywattana C, Dejthevaporn T, Virojchaiwong P, Sripramote M. Transvaginal Saline Sonosalpingography for The Assessment of Tubal Patency. assessment. 2002;14(3).

10. Singhal A, Agrawal K, Khuteta R. Comparison of Transvaginal Sonosalpingography to Chromolaparoscopy for Evaluation of Tubal Patency in Infertile Patients. IOSR Journal of Dental and Medical Sciences (IOSR-JDMS). 2011;1(15):47-9.

11. Hajishafiha M, Zobairi T, Zanjani VR, Ghasemi-Rad M, Yekta Z, Mladkova N. Diagnostic value of sonohysterography in the determination of fallopian tube patency as an initial step of routine infertility assessment. Journal of Ultrasound in Medicine. 200928(12):1671-7.

12. Gandotra N, Sharma A, Rizvi SM. Comparison of Laparoscopy and Hysterosalpingography in Diagnosis of Tubal Occlusion. 2015.

13. Malik B, Patil S, Boricha BG, Kurkal N, Choudhry M. A comparative study of the efficacy of sonosalpingography and hysterosalpingogram to test the tubal patency in all women with primary and secondary infertility. Ultrasound quarterly. 2014;30(2):139-43.

14. Geetha D, Thilagavathy D. Comparative Evaluation of Tubal Patency by sterosalphingography and Laparoscopicchromopertubation. IOSR Journal of Dental and Medical Sciences. 2016;15(08):53-57.

15. Seal SL, Ghosh D, Saha D. Comparative evaluation of sonosalpingography, hysterosalpingography and laparoscopy for determination of tubal patency. J Obstet Gynecol India. 2007;57:158-61.

Cite this article as: Agrawal R, Shrivastava D. Role of hysterosalpingography in evaluation of tubal factors and its comparison with sonosalpingography. Int J Reprod Contracept Obstet Gynecol 2017;6:1216. 